\title{
Next generation sequencing reveals distinct fecal pollution signatures in aquatic sediments across gradients of anthropogenic influence
}

\author{
Gian Marco Luna, ${ }^{1}$ Grazia M. Quero, ${ }^{2}$ Laura Perini ${ }^{2}$ \\ ${ }^{1}$ CNR-ISMAR Institute of Marine Sciences, National Research Council, Largo Fiera della Pesca 2, 60125 Ancona, Italy; ${ }^{2}$ CNR-ISMAR \\ Institute of Marine Sciences, National Research Council, Arsenale Tesa 104, 30122 Venezia, Italy \\ *Corresponding author: gianmarco.luna@ismar.cnr.it
}

\begin{abstract}
Aquatic sediments are the repository of a variety of anthropogenic pollutants, including bacteria of fecal origin, that reach the aquatic environment from a variety of sources. Although fecal bacteria can survive for long periods of time in aquatic sediments, the microbiological quality of sediments is almost entirely neglected when performing quality assessments of aquatic ecosystems. Here we investigated the relative abundance, patterns and diversity of fecal bacterial populations in two coastal areas in the Northern Adriatic Sea (Italy): the Po river prodelta (PRP, an estuarine area receiving significant contaminant discharge from one of the largest European rivers) and the Lagoon of Venice (LV, a transitional environment impacted by a multitude of anthropogenic stressors). From both areas, several indicators of fecal and sewage contamination were determined in the sediments using Next Generation Sequencing (NGS) of 16S rDNA amplicons. At both areas, fecal contamination was high, with fecal bacteria accounting for up to $3.96 \%$ and $1.12 \%$ of the sediment bacterial assemblages in PRP and LV, respectively. The magnitude of the fecal signature was highest in the PRP site, highlighting the major role of the Po river in spreading microbial contaminants into the adjacent coastal area. In the LV site, fecal pollution was highest in the urban area, and almost disappeared when moving to the open sea. Our analysis revealed a large number of fecal Operational Taxonomic Units (OTU, 960 and 181 in PRP and LV, respectively) and showed a different fecal signature in the two areas, suggesting a diverse contribution of human and non-human sources of contamination. These results highlight the potential of NGS techniques to gain insights into the origin and fate of different fecal bacteria populations in aquatic sediments.
\end{abstract}

Key words: $16 \mathrm{~S}$ rDNA; fecal bacteria; aquatic sediments; sewage; lagoon.

Received: April 2016. Accepted: June 2016.

\section{INTRODUCTION}

The anthropogenic impact is significantly altering aquatic ecosystems (Vörösmarty et al., 2010; Elliott and Elliott, 2013), by means of a plethora of pressures that include chemical pollution and wastewater discharge, eutrophication, hypoxia, utilization of living resources, habitat destruction and climate change effects (Halpern et al., 2008). Aquatic sediments, acting as repositories of materials and solutes deposited from or diffused through the water column, accumulate chemical and biological contaminants (Ridgway and Shimmield, 2002). This holds true also for microbiological pollutants, including autochthonous and pathogenic microbes of fecal origin, that reach the aquatic environment by a variety of routes and can spread diseases to human and aquatic populations, with important socio-economic, sanitary and environmental consequences (Stewart et al., 2008).

A number of studies have so far investigated the presence and distribution of fecal bacteria in aquatic sediments. The majority of these studies have addressed the traditional fecal indicators, such as total coliforms, Escherichia coli and intestinal enterococci, which are world- wide used for assessments of aquatic ecosystems quality (Field and Samadpour, 2007 and references therein; Liang et al., 2015). These studies have shown that substantial populations of fecal bacteria can be often retrieved in lagoon, estuarine and coastal sediments (An et al., 2002; Luna et al., 2010; Pachepsky and Shelton, 2011; Perini et al., 2015), suggesting that sediments are environmental reservoirs of fecal bacteria. However, the reliability of these indicators has been recently questioned, as they can persist and regrow in the environment, they are recovered also in absence of obvious fecal sources, and following the discovery of environmentally-adapted populations of E. coli (Luo et al., 2011; Byappanahalli et al., 2012). Altogether, these issues have stimulated new studies, aimed at identifying alternative and more reliable indicators of fecal pollution, able to identify risks to human health and improve monitoring strategies (Stewart et al., 2008). Kreader (1995) pioneered the use of fecal anaerobes within the genus Bacteroides as more reliable fecal indicators, and highlighted their potential to distinguish human from non-human sources of pollution. Since then, several studies have been performed to discover and test new indicators of fecal pollution in water (reviewed in 
McLellan and Eren, 2014), while studies of alternative fecal indicators in aquatic sediments have been rare (Kim and Wuertz, 2015). On the light of the recognized role of aquatic sediments as reservoir of fecal bacteria, the urgency of expanding our poor knowledge in the sedimentary environment becomes manifestly evident.

Recent studies have shown the usefulness of Next Generation Sequencing (NGS) technologies in water quality assessments (Vierheilig et al., 2015). NGS techniques can provide insights into the ecology of microbe-mediated processes (such as biodegradation of contaminants and algal blooms) influencing water quality, but can also be extremely useful to identify an array of other taxa that could serve as indicators of fecal contamination in aquatic environments (Tan et al., 2015). This holds true for those NGS methods that target small subunit rRNA hypervariable regions, which are able to resolve microbial community composition in environmental samples, and to provide information on source-specific phylotypes and/or assemblages of phylotypes (Newton et al., 2011, 2013). Fisher et al. (2015) have recently shown the potential of sequencing the $\mathrm{V} 6$ region of the $16 \mathrm{~S} r R N A$ genes to discern between human versus non-human fecal sources. $\mathrm{Cu}$ mulatively, these emerging studies show the potential of NGS as powerful tool in detecting alternative fecal indicators also in aquatic sediments.

We report here the results of an investigation, carried out in two different aquatic environments in the Northern Adriatic Sea (Italy), with the aim of assessing the presence and spatial distribution of traditional and alternative (feces-associated and sewer infrastructure-associated) fecal indicators by using NGS methods targeting the $16 \mathrm{~S}$ $r R N A$ bacterial gene. This study is, to the best of our knowledge, among the first performed so far to explore the presence and spatial variability of alternative fecal indicators in different aquatic sediments, providing potentially useful insights for tracking the source and fate of fecal bacteria in aquatic sediments.

\section{METHODS}

\section{Description of the study areas}

Sediments were collected in two coastal areas located in the Northern Adriatic Sea: the Po river prodelta (hereafter defined PRP) and the Lagoon of Venice (hereafter defined LV), supposed to be exposed to different types of fecal contamination. The PRP receives a significant discharge of contaminants from one of the largest rivers in Europe (Boldrin et al., 2005). The river discharges a mean of 1500 $\mathrm{m}^{3} \mathrm{~s}^{-1}$ of freshwater (with peaks up to $>10,000 \mathrm{~m}^{3} \mathrm{~s}^{-1}$ during floods), that produces a freshwater plume able to influence the microbial diversity and functioning of the adjacent coastal ecosystem (Manini et al., 2004, Quero et al., 2015).
The Po experiences typically major floods, which transport large amounts of suspended sediments and associated pollutants to the sea, that can be stored or transported offshore to the adjacent marine areas (Correggiari et al., 2005). Many studies have shown that the coastal area in front of the delta is severely chemically polluted, as the river carries yearly tons of anthropogenic chemicals collected from the Po valley and the river tributaries, including emerging contaminants (Casatta et al., 2015). The LV, among the largest lagoons in the Mediterranean, is a microtidal, semi-closed lagoon connected to the Adriatic Sea by three openings (inlets), influenced by a tidal semidiurnal regime (Cucco and Umgiesser, 2006). The tidal regime governs the water exchange with the adjacent open sea, and largely influences the renewal capacity of the lagoon basin. The LV is historically impacted by a multitude of anthropogenic stressors, among which one of the largest industrial plants of Italy located on the nearby mainland, touristic and commercial ports, several small tributaries (that carry around $30-35 \mathrm{~m}^{3}$ $\mathrm{s}^{-1}$ of freshwater; Zuliani et al., 2005), agricultural and municipal wastes. As far as the fecal contamination is concerned, an important source of contamination is the city of Venice which, due to its history and unique building architecture, has never been provided with a modern and efficient sewage treatment system (Sfriso and Facca, 2013). Consequently, only partially treated effluents from a large number of domestic and commercial inputs are discharged daily into the city canals, determining a diffuse contamination and the accumulation of fecal bacteria in sediments and live macroalgae (Quero et al., 2015; Perini et al., 2015).

\section{Sampling activities}

In the PRP area, sampling was performed between $10^{\text {th }}$ and $14^{\text {th }}$ June 2013 in front of the outlets of the main branches of the river delta. The sampling design included 11 stations (Fig. 1), distributed along coast-to-open sea transects, at depths comprised between 9.5 and 20.5 meters. The geographic coordinates (as longitude and latitude) and water depths of the stations were as follows: 1 (12.543 E, $44.99 \mathrm{~N}, 12 \mathrm{~m}), 2(12.556 \mathrm{E}, 44.993 \mathrm{~N}, 20.5 \mathrm{~m}), 3$ (12.571 E, $44.968 \mathrm{~N}, 9.5 \mathrm{~m}), 4(12.576 \mathrm{E}, 44.971 \mathrm{~N}, 15$ m), $5(12.581 \mathrm{E}, 44.974 \mathrm{~N}, 19 \mathrm{~m}), 6(12.573 \mathrm{E}, 44.955 \mathrm{~N}$, $10.5 \mathrm{~m}), 7(12.585 \mathrm{E}, 44.952 \mathrm{~N}, 14 \mathrm{~m}), 8(12.558 \mathrm{E}$, $44.929 \mathrm{~N}, 11 \mathrm{~m}), 9(12.573 \mathrm{E}, 44.919 \mathrm{~N}, 14.6 \mathrm{~m}), 10$ $(12.538 \mathrm{E}, 44.891 \mathrm{~N}, 14.8 \mathrm{~m})$ and $11(12.558 \mathrm{E}, 44.886$ $\mathrm{N}, 17.5 \mathrm{~m}$ ). The sampling transects were in front of the outlets of the main branches of the river delta. The spatial distribution of the stations was thought to follow the possible deposition route of pollutants transported by an exceptional flood event, like the one that occurred in the third week of May 2013, with a maximum flow rate of $6830 \mathrm{~m}^{3} \mathrm{~s}^{-1}$. More details about the sampling activities and the characteristics of the sampling stations in the PRP are reported in Quero et al. (2015). 
In the LV area, sampling was performed during the autumn season $\left(21^{\text {st }}-22^{\text {th }}\right.$ October 2014), chosen as the period of highest river runoff, expected to increase the load of fecal bacteria within the lagoon. The sampling design included 5 sampling stations (Fig. 1), at depths comprised between 5.4 and $16 \mathrm{~m}$, distributed across a gradient of putative contamination from the inner part of the lagoon to the open sea. The geographic coordinates (longitude and latitude) and water depth of the stations were as follows: Industrial Port (12.219 E, 45.438 N, 5.4 m), Inner Lagoon (12.258 E, 45.448 N, $7.2 \mathrm{~m}$ ), Cruise Port (12.311 E, 45.436 N, $12.1 \mathrm{~m}$ ), City Centre (12.352 E, 45.431 N, 7.1 $\mathrm{m})$ and Open Sea (12.508 E, $45.313 \mathrm{~N}, 16 \mathrm{~m})$. In both areas, sediments were collected using a Van Veen grab sampler (sampling surface $0.1 \mathrm{~m}^{2}$ ), onboard small research vessels (a privately operated one in the PRP area, and the 'Litus' boat operated by ISMAR-CNR in the LV one). Once onboard, the uppermost $0-2 \mathrm{~cm}$ layer of sediment was immediately placed, using sterile spatulas, in sterile containers for their immediate transport at $4^{\circ} \mathrm{C}$ to the laboratory, where the samples were stored at $-20^{\circ} \mathrm{C}$ until analysis.

\section{Analyses of fecal bacteria using Illumina sequencing of the 16S rRNA gene}

DNA was extracted from one gram of each sediment sample using the PowerSoil ${ }^{\mathbb{B}}$ DNA Isolation Kit (MoBio

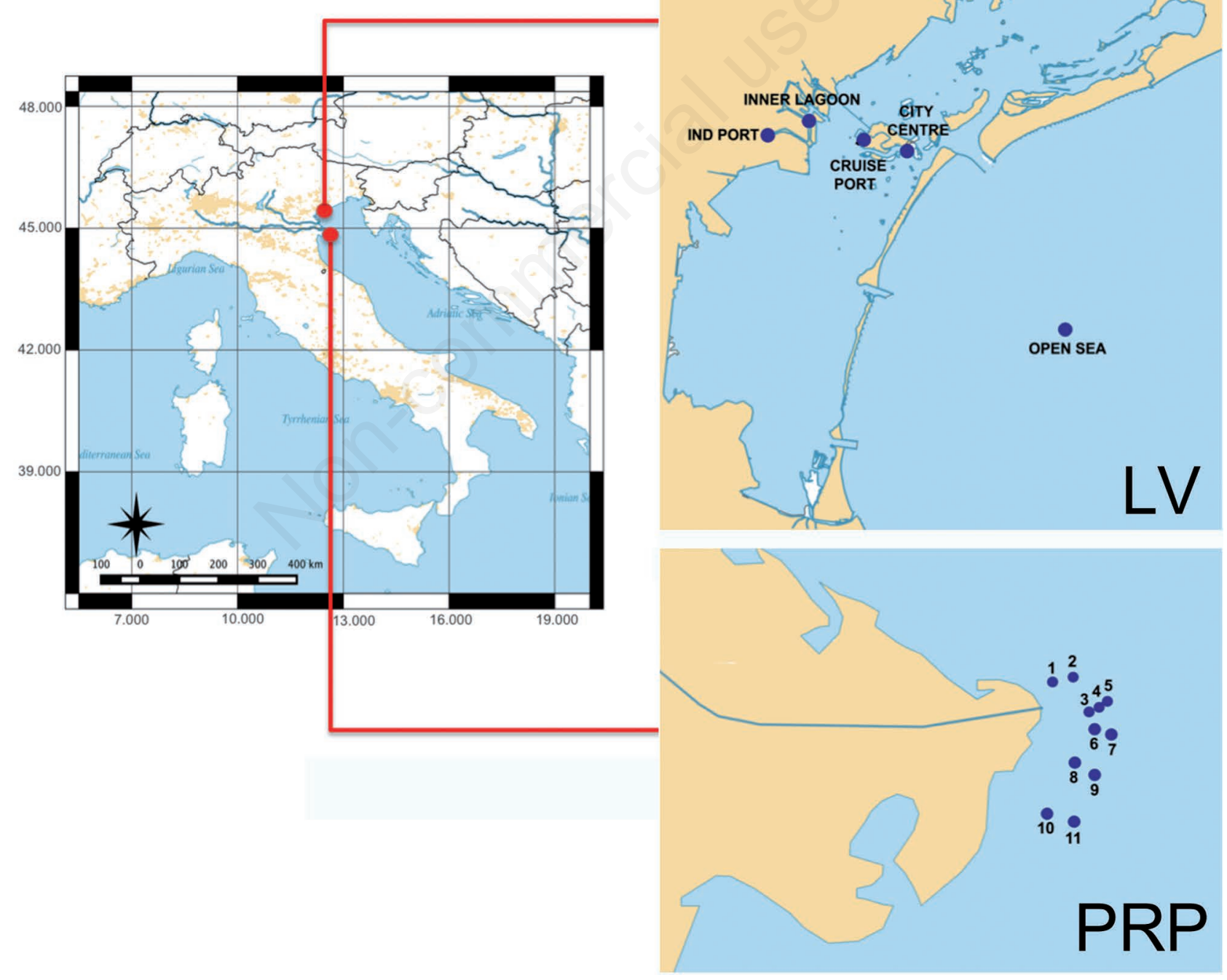

Fig. 1. The two study sites in the Northern Adriatic Sea (Italy), with indication and name of the sampling stations (blue dots). Latitude (N) and longitude (E) are reported; LV, Lagoon of Venice; PRP, Po river prodelta. 
Laboratories Inc., California), according to the manufacturer's instructions with some slight modifications to increase the DNA yield and quality. These modifications included two additional vortexing steps (following the one which is recommended by the manufacturer) at the maximum speed for $2 \mathrm{~min}$, each one being preceded by an incubation at $70^{\circ} \mathrm{C}$ for $5 \mathrm{~min}$, and by one more washing step with Solution C5 as an additional removal step for contaminants. The concentration of each DNA extract was determined spectrophotometrically using NanoDrop ( Thermo Scientific) and the DNA was stored at $-80^{\circ} \mathrm{C}$ until PCR. Illumina Miseq V3 sequencing were carried out on the hypervariable V3 and V4 regions of the 16S rRNA gene by amplifying using the $341 \mathrm{~F}\left(5^{\prime}-\mathrm{CCTACGGGNG-}\right.$ GCWGCAG-3') and 785R (5'-GACTACHVGGGTATCTAATCC $-3^{\prime}$ ) universal bacterial primers (Eiler et al., 2012). Paired-end reads were quality checked (with default settings and minimum quality score of 20) and analyzed with QIIME v1.8.0 software package (Quantitative Insights Into Microbial Ecology; Caporaso et al., 2010). Reads were clustered into OTUs by using UCLUST v1.2.22 (Edgar, 2010) with a $>97 \%$ similarity threshold with an open-reference OTU picking strategy and default settings. Chimeras were detected by using USEARCH v6.1 (Edgar, 2010). Chimera checking and taxonomy assignment was performed using Greengenes 13.8 as reference database (DeSantis et al., 2006). To account for differences in the sequencing effort among samples, abundances in each sample were normalized to the number of sequences of the sample showing the lowest number of reads. The sequences of the PRP area have been submitted to the SRA (Sequence Read Archive; accession numbers SRP061637), while those for the LV are currently being submitted.

\section{Data elaboration and statistical analyses}

Within each of the bacterial assemblage, we searched for those OTUs identified as belonging to the traditional fecal indicator taxa (i.e., the family Enterobacteriaceae, that includes the genus Escherichia, and the genus Enterococcus), and those OTUs belonging to the alternative fecal indicator taxa, according to the approach proposed by Newton et al. (2013). As alternative indicators, we searched for OTUs belonging to five feces-associated bacterial families (Bacteroidaceae, Porphyromonadaceae, Clostridiaceae, Lachnospiraceae and Ruminococcaceae) and three sewer infrastructure-associated bacterial genera (Acinetobacter, Arcobacter and Trichococcus), that we used here as signatures of fecal (human and non-human) and sewage contamination, respectively. This distinction was based on the study by Newton et al. (2013), who reported that five feces-associated bacterial families were prevalent (up to $85 \%$ of the total sequences) in the feces of animals and humans while, on the other hand, three sewer infrastructure-associated genera were very abundant in the sewage samples while not prevalent in human feces (only 33 sequences recovered out of a $>1.2$ million sequences of a human fecal dataset). Vandewalle et al. (2012) reported that only a small fraction of OTUs in sewage matched sequences from human fecal samples, and suggested that these sewage-associated taxa, that thrive within the sewer system, may serve as useful adjuncts to fecal indicators for tracking sewage pollution in surface waters. The Spearman-Rank correlation analysis was performed to test for relationships between the relative abundance of traditional and alternative fecal indicators. Correlation coefficients (r) were considered significant at P-values less than 0.05. Differences in the composition of fecal bacterial communities between the sampling areas, and between groups of stations within each of the two areas, were assessed by using the analysis of similarity (ANOSIM) tool based on a Bray-Curtis similarity matrix. The presence of statistical differences between samples is indicated by a significance level at $\mathrm{P}$-values less than 0.05 . To assess differences in the composition of indicator OTUs between the sampling areas, we applied univariate distance-based permutational analyses of variance (PERMANOVA). The statistical analyses were carried out using a sampling design, that considered the Area as fixed factor as source of variance, with 2 levels (PRP and LV). The ANOSIM and PERMANOVA analyses were performed using the PRIMER 6 software (http://www.primer-e.com/).

\section{RESULTS \\ Relative abundance of traditional, feces- and sewage-associated indicators}

At both areas, sequence analyses of the sediment samples revealed evidences for a marked and diffuse fecal signature that was, however, significantly different between the two areas (ANOSIM, $r=0.314, \mathrm{P}<0.05$ ). In the PRP area, the relative abundance of traditional indicators (Fig. 2A) accounted for 0.01 to $0.19 \%$ of the bacterial assemblage in the case of Enterobacteriaceae, and for 0 (no sequences detected) to $0.01 \%$ in the case of Enterococcus. In the same study area, the relative abundance of alternative fecal indicators was quite higher than that of traditional indicators. The contribution of the feces-associated indicators (Fig. 2C) was in the range $0.08-2.13 \%$ (Lachnospiraceae), $0.17-0.53 \%$ (Clostridiaceae), $0-0.14 \%$ (Porphyromonadaceae), $0-0.04 \%$ (Bacteroidaceae) and $0.08-0.63 \%$ (Ruminococcaceae), while the contribution of the sewage-associated indicators (Fig. 2E) was in the range $0-0.17 \%$ (Arcobacter), 0.06-0.57\% (Acinetobacter), with only one or two sequences per sample assigned to the Trichococcus genus (only at the stations 4, 5,6 and 
8). The cumulative contribution of all the sequences belonging to the traditional, feces- and sewage-associated indicators was in the range $0.49-3.96 \%$ of the bacterial assemblages (on average 1.63\%).

In the LV area, the level of fecal contamination was
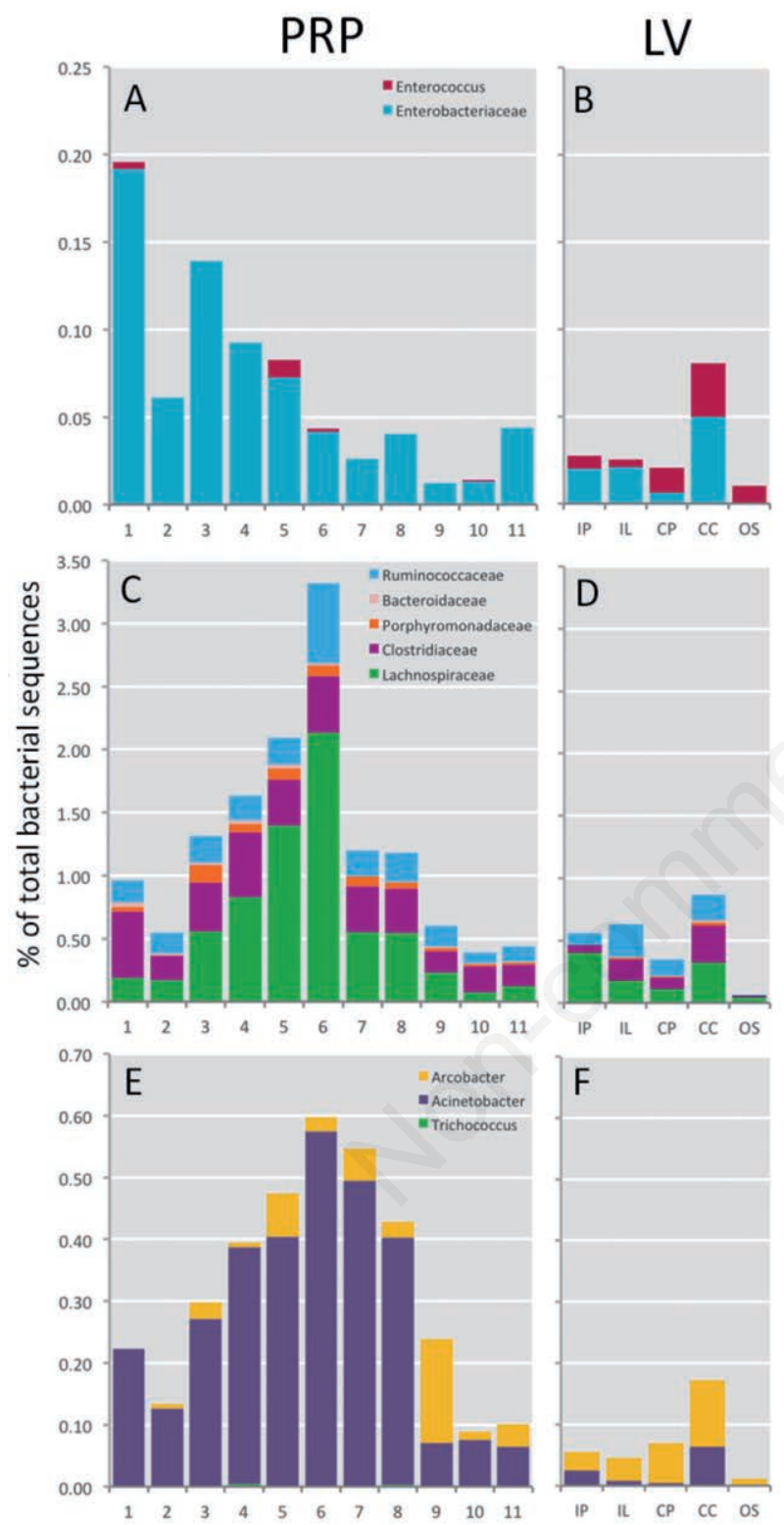

Fig. 2. Bar plots of the relative abundance of $16 \mathrm{~S}$ rDNA sequences belonging to: A, B) the traditional fecal indicator bacterial taxa (Enterobacteriaceae and Enterococcus); C, D) the feces-associated bacterial families (Lachnospiraceae, Clostridiaceae, Porphyromonadaceae, Bacteroidaceae and Ruminococcaceae); and E, F) the sewage-associated bacterial genera (Arcobacter, Acinetobacter and Trichococcus) in the sediments of the two sites. In the LV site: IP, industrial port; IL, inner lagoon; CP, cruise port; CC, city centre; OS, open sea. overall reduced when compared to the PRP area. As far as the traditional indicators are concerned, these were observed in the LV area at all stations (Fig. 2B), in the range $0-0.05 \%$ (Enterobacteriaceae) and 0.004-0.03\% (Enterococcus). The relative abundance of the feces-associated indicators (Fig. 2D) was higher and accounted for 0.05$0.40 \%$ (Lachnospiraceae), 0.01-0.29\% (Clostridiaceae), $0-0.02 \% \quad$ (Porphyromonadaceae), $0-0.02 \%$ (Bacteroidaceae) and $0.001-0.27 \%$ (Ruminococcaceae), while the contribution of the sewage-associated indicators (Fig. 2F) was in the range $0.01-0.11 \%$ (Arcobacter), 0 $0.06 \%$ (Acinetobacter), with no sequences assigned to the genus Trichococcus. The cumulative contribution of all of the sequences belonging to the traditional and alternative indicators accounted from 0.08 to $1.12 \%$ of the bacterial assemblage (on average $0.60 \%$ ).

\section{Spatial patterns of fecal indicators in the two areas}

In the PRP area, the fecal contamination in stations located closer to the coast (stations 1, 3, 4, 5, 6, 8 and 10; average relative abundance $2.0 \%$ ) was two-fold higher that in offshore stations $(2,7,9$ and 11 ; average $0.99 \%)$. The highest abundance of fecal indicators as a whole (i.e., summing up traditional and alternative indicators) was observed in the stations located right in front of the main outlet of the Po river (stations 4, 5, and 6; up to $3.96 \%$ in the station 6). The relative abundance of traditional indicators didn't show significant correlation either with the feces- or with the sewage-associated indicators ( $\mathrm{P} \geq 0.05$ for both relationships), whereas the feces- and sewage-associated indicators were significantly and positively related $(\mathrm{r}=0.83, \mathrm{P}<0.01)$.

In the LV area, the fecal contamination was much higher inside the lagoon (stations Ind. Port, Inner Lagoon, Cruise Port and City Centre; average relative abundance $0.73 \%$ ), and only weakly detectable in the open sea station (relative abundance $0.08 \%$ ). Within the lagoon, the highest abundance of fecal indicators as a whole was observed in the station located closer to the city center of Venice $(1.12 \%)$, followed by the two stations located close to the industrial area (station Ind. Port, $0.64 \%$ ) and the mainland (Inner Lagoon, $0.70 \%$ ). In the LV area the different types of fecal indicators were positively and significantly correlated $(\mathrm{r}=0.82, \mathrm{P}<0.05$ between traditional and feces-associated indicators; $\mathrm{r}=0.92, \mathrm{P}<0.01$ between traditional and sewage-associated indicators). The feces- and sewage-associated indicators were also significantly and positively correlated $(\mathrm{r}=0.751, \mathrm{P}<0.05)$.

\section{Traditional, fecal and sewage indicator OTUs}

The number of OTUs that were affiliated with each of the fecal indicator groups varied widely between areas and among stations in each area, ranging from 0 to 266 
OTUs depending on the fecal indicator (Tab. 1). The results of univariate PERMANOVA revealed a significant effect of the factor area $(\mathrm{P}<0.01)$. In the PRP area, the results are summarized by grouping the stations located closer to the coast $(1,3,4,5,6,8$ and 10) and those located more offshore (stations 2, 7, 9 and 11). This choice was supported by the ANOSIM analysis, that demonstrated significant differences, in terms of OTU community composition, between these two groups of stations (ANOSIM, $\mathrm{P}<0.05$ ). In this area, the cumulative number of OTUs (i.e., the sum of all OTUs recorded at all stations) belonging to the traditional indicators was 46 for Enterobacteriaceae and 4 for Enterococcus (only observed in the more coastal stations). The number of OTUs within the feces-associated indicators was much higher: 176 and 98 for Lachnospiraceae (coastal and offshore stations, respectively), 169 and 141 (Clostridiaceae), 55 and 36 (Porphyromonadaceae), 22 and 9 (Bacteroidaceae), 132 and 93 (Ruminococcaceae). The number of OTUs associated with the sewage-associated indicators was 3 and 0 for Trichococcus (coastal and offshore stations, respectively), 69 and 54 (Acinetobacter), 19 and 34 (Arcobacter). Overall, in the PRP area the number of OTUs in the coastal stations was higher than in the offshore ones, with only one exception (i.e., Arcobacter OTUs more abundant in offshore than in coastal stations).

In LV area, the cumulative number of OTUs belonging to the traditional indicators was 5 and 2 (for Enterobacteriaceae and Enterococcus, respectively). The cumulative number of the fecal-associated indicator OTUs was larger compared to the traditional ones, corresponding to 38
(Lachnospiraceae, range among sampling stations 4-18), 37 (Clostridiaceae, range 5-18), 16 (Porphyromonadaceae, range 0-10), 18 (Bacteroidaceae, range 0-9) and 22 OTUs (Ruminococcaceae, range 0-10). At the same time, the number of OTUs belonging to the sewage-associated indicators was 12 for Acinetobacter (range 0-5) and 31 for Arcobacter (range 4-20), with no OTUs belonging to Trichococcus. The highest number of OTUs was observed in the lagoon stations (namely, at stations Ind. Port, Inner Lagoon and City Centre. The station located in the open sea showed only 14 OTUs for the entire pool of fecal indicators (traditional, feces- and sewage-associated).

\section{DISCUSSION}

In this study, we aimed at examining the presence, prevalence and spatial distribution of traditional and alternative fecal indicators in a range of aquatic sediments, collected in transitional, estuarine and coastal marine areas along gradients of anthropogenic influence. We used NGS of 16S rRNA gene amplicons to identify and track fecal indicator bacteria within complex benthic microbial assemblages, by taking advantage of the method recently proposed by Newton et al. (2013), that allows to potentially discriminate between feces-associated and sewageassociated bacteria. The presence and distribution patterns of alternative indicators in the sediments were then compared with those of traditional indicators (Escherichia coli, within the Enterobacteriaceae family, and enterococci) that are utilized worldwide to assess fecal pollution

Tab. 1. Number of OTUs affiliated with the different fecal indicator bacteria in the two study sites. For the Po River prodelta site, results are summarized by summing all the OTUs observed at stations $1,3,4,5,6,8$ and 10 (stations close to the coast) and those observed at stations 2, 7, 9 and 11 (offshore stations).

\begin{tabular}{|c|c|c|c|c|c|c|c|c|c|}
\hline \multirow{4}{*}{$\begin{array}{l}\text { Microbial } \\
\text { indicator }\end{array}$} & \multicolumn{3}{|c|}{ PRP } & \multicolumn{5}{|c|}{ LV } & \multirow{4}{*}{$\begin{array}{l}\text { Cumulative } \\
\text { no. of OTUs }\end{array}$} \\
\hline & \multicolumn{3}{|c|}{ Number of OTUs } & \multicolumn{5}{|c|}{ Number of OTUs } & \\
\hline & Stations close & Offshore & Cumulative & \multicolumn{5}{|c|}{ Stations within the lagoon } & \\
\hline & to the coast & stations & no. of OTUs & IP & IL & $\mathbf{C P}$ & $\mathrm{CC}$ & Open sea & \\
\hline \multicolumn{10}{|l|}{ Traditional } \\
\hline Enterobacteriaceae & 27 & 28 & 46 & 1 & 5 & 1 & 3 & 0 & 5 \\
\hline Enterococcus & 4 & 0 & 4 & 1 & 1 & 1 & 3 & 1 & 2 \\
\hline \multicolumn{10}{|l|}{ Feces-associated } \\
\hline Lachnospiraceae & 176 & 98 & 266 & 17 & 18 & 9 & 9 & 4 & 38 \\
\hline Clostridiaceae & 169 & 141 & 231 & 10 & 16 & 18 & 10 & 5 & 37 \\
\hline Porphyromonadaceae & 55 & 36 & 70 & 3 & 7 & 2 & 10 & 0 & 16 \\
\hline Bacteroidaceae & 22 & 9 & 28 & 3 & 9 & 4 & 8 & 0 & 18 \\
\hline Ruminococcaceae & 132 & 93 & 187 & 6 & 10 & 10 & 6 & 0 & 22 \\
\hline \multicolumn{10}{|l|}{ Sewage-associated } \\
\hline Trichococcus & 3 & 0 & 3 & 0 & 0 & 0 & 0 & 0 & 0 \\
\hline Acinetobacter & 69 & 54 & 85 & 5 & 4 & 1 & 3 & 0 & 12 \\
\hline Arcobacter & 19 & 34 & 40 & 20 & 9 & 8 & 17 & 4 & 31 \\
\hline
\end{tabular}

PRP, Po River prodelta; LV, lagoon of Venice; OTU, Operational Taxonomic Units; IP, industrial port; IL, inner lagoon; CP, cruise port; CC, city centre; OS, open sea. 
in aquatic environments. Recently, a large body of studies have identified and tested alternative indicators of fecal pollution in aquatic systems, by exploiting the NGS technologies to provide unprecedented inventories of microbial communities in aquatic samples (McLellan and Eren, 2014). However, while a large number of studies have investigated the presence and spatial patterns of alternative indicators in water (Savichtcheva and Okabe, 2006; Liang et al., 2015), similar studies in sediments have been rare (Kim and Wuertz, 2015). This lack of knowledge is surprising, given the recognized role of aquatic sediments as reservoir of fecal bacteria (Luna et al., 2010), and their potential to favor the persistence of fecal microbes and to contaminate the overlying water through resuspension, which likely poses important public health and environmental threats.

At both study areas, we found evidences for an extensive microbial pollution that was testified, despite at different extent, by the presence of traditional, feces- and sewage-associated indicators. These indicators accounted cumulatively for a variable fraction of benthic assemblages with peaks, as in the case of the most polluted sediments, up to $3.96 \%$. At both study areas, the magnitude of the fecal signature decreased with increasing distance from the sources of pollution, which underlines the usefulness of this approach, that includes also the alternative indicators, to track the fecal pollution in aquatic sediments. The presence of fecal pollution in the two sites was not unexpected, since they are both subjected to a significant anthropogenic pressure, and likely receive important loads of fecal bacteria. The PRP coastal area receives a significant discharge of sediments and pollutants from the largest Italian river, especially after the floods that occur on a seasonal (biannual) frequency and, also, as episodic short-term events (Palinkas et al., 2005). Its drainage basin contributes to more than $35 \%$ of the national agricultural, livestock and industrial production, that originates organic loads estimated in $114 \times 10^{6}$ inhabitant equivalents (Casatta et al., 2015). However, while the presence of chemical pollutants in the coastal area near the mouth of the Po river has been largely reported (Romano et al., 2013), this is the first report on the presence of extensive fecal pollution in these sediments. The largest fecal contamination was observed in the stations located in front of mouth of the Pila distributary, which is the main outlet of the river and can discharge up to $70 \%$ of the sediment load delivered to the sea. However, the fecal signature was also observed in stations located downstream of this main mouth, that suggests either a fecal input from the other minor distributaries, and/or the potential of fecal bacteria of being distributed over a large coastal area. This bacterial spread may occur when the high fluvial discharge coincides with energetic physical oceanographic conditions, preventing deposition in shal- low waters and favoring sediment dispersion in seabed deposits located offshore and downstream of the mouth (Palinkas et al., 2005). Our finding of a large reservoir of fecal bacteria in the Po prodelta sediments poses a claim for potential health consequences, given the potential of sediment bacteria of being re-suspended and transported southward, where several bathing beaches and touristic destinations are present. Nevertheless we point out here that further studies are needed to investigate the ability of the different fecal bacterial populations, including the feces- and sewage-associated bacteria, to persist or decay once they reach the marine environment, and of being potentially transported toward adjacent coastal areas in presence of specific hydrological conditions.

The finding of a diffuse fecal contamination in the LV area, especially in the stations more exposed to anthropogenic impacts, likely depends on the wide variety of human impacts, in the form of large industrial plants, touristic and commercial ports, rivers, agricultural and municipal wastes, that have affected this vulnerable transitional environment in the last years (Micheletti et al., 2011). Our results show that the highest fecal contamination is observed in the area closer to the city of Venice, confirming recent findings of a chronic fecal pollution (Perini et al., 2015), but also that other areas of the Venice lagoon, located closer to the mainland, receive important loads of bacteria of fecal origin. This may be due to multiple delivery routes discharging in the inner part of the lagoon, that include runoff, outfall discharge, sewer overflows (that causes untreated sewage to be released), presence of tributaries, and other human activities. It is worth noticing that a signal, despite weak, of fecal contamination was observed also in the sediments of the open sea station. We speculate that the presence of fecal pollutants in this area, which is relatively far by obvious sources of pollution, could be the consequence of fecal discharges by offshore point sources and/or by the underwater submarine wastewater pipes present in the area (Scroccaro et al., 2010), that may disperse microbial pollutants over vast marine areas.

We report here that different aquatic sediments subjected to anthropogenic influence contain important proportions of traditional indicator bacteria, as well as fecal bacteria representing signatures of fecal (human and animal) and sewage sources. At both areas, the relative abundance of fecal- and sewage-associated bacteria always exceeded that of the traditional indicators. Sediments are a potentially favorable environment for fecal microorganisms survival, and this may be especially true for many of the alternative indicators (such as Bacteroidales), that do not survive well in water due to their obligate anaerobic physiology (Bae and Wuertz, 2015) but may persist longer in low-oxygen or anoxic layers that are common in sediments. In both areas, we found that the fecal signature was more evident than the sewage signature. However, the av- 
erage ratio of the fecal pollution signature to the sewage pollution signature was different in the two areas. In PRP, the average contribution of the feces-associated taxa was $1.244 \%$, a percentage 3.9-fold higher than that of the sewage-associated taxa $(0.320 \%)$. Conversely, in the LV area, the average contribution of feces-associated taxa was $0.602 \%$ (excluding the open sea station), a percentage 7.05-fold higher than that of the sewage-associated indicators $(0.085 \%)$. The prevalence of different fecal bacterial signatures in the two areas suggests the presence of different fecal sources. The higher ratio of feces- to sewage-associated bacteria observed in the lagoon of Venice suggests that human/animal sources of pollution are more important than sewage in polluting this area while, in the Po prodelta area, the sewage pollution appears to be an important source. The sewage pollution in the PRP area is particularly evident in the Acinetobacter signature which is, on average, 14 -fold more abundant than in the LV site. This genus is the most important in sewage (Newton et al., 2013), and its recovery in sediments suggests that it may be a reliable signature of sewage pollution also in the benthic environment. It remains to be determined whether members of this genus are adapted to survive in aquatic sediments, and how long are their decay rates once they reach the sedimentary environment. The importance of sewage in contributing to pollution in the Po prodelta is also confirmed by the recovery of another sewage-associated genus (Trichococcus) that, though with only a few sequences per sample, was observed only in this area and not in the Venice lagoon.

A very large number of fecal OTUs, accounting for a total of 960 and 181 OTUs (in the PRP and LV areas, respectively), were observed in the sediments under scrutiny. The largest number of OTUs was observed in the Po prodelta area. This may suggest the existence, in this area, of multiple delivery mechanisms containing multiple fecal sources, that likely originate from the large drainage basin, and resulting in more complex fecal OTU signatures than those observed in the LV sediments. In many cases and at both areas, fecal bacteria populations were dominated by few dominant OTUs. A closer examination of the top most abundant fecal OTUs in the two sites provided additional insights, useful to potentially distinguish among different sources of pollution. In the PRP area, the traditional indicators showed dominance of one Enterobacteriaceae OTU (range 5-177 sequences per sediment sample) that showed $100 \%$ Blast identity with Escherichia coli strain 732 (accession number CP015138). The enterococci populations, that were poorly represented at this area, were dominated by one OTU affiliated with Enterococcus casseliflavus isolated from cow rumen (accession number KT630829), suggesting that cattle may be an important route of fecal pollution in this area. Conversely, in the LV area, the dominant Enterobacteriaceae
OTU was affiliated with Yersinia kristensenii (accession number HG938308.1) while the dominant enterococcal OTU, especially abundant in the station closer to the city center, showed a top Blast match with Catellicoccus marimammalium (accession number KF251005.1) isolated from gulls' feces. In the Venice urban area, populations of urban gulls have increased exponentially in the last years (Rock, 2012). Our findings indicate that they can contribute as an additional source of fecal contamination in the lagoon, which deserves further investigations.

As far as the fecal- and sewage-associated OTUs are concerned, the same analysis of the identity of the dominant OTUs revealed also interesting additional insights. The dominant Acinetobacter OTUs in the LV area, particularly abundant in the station closer to the city center, showed a top Blast match with an uncultured Acinetobacter (HQ742373.1) associated with the human intestine, confirming human fecal pollution as an important contamination route in the city (Perini et al., 2015). Conversely, the analyses of some of the dominant Lachnospiraceae OTUs showed, at both PRP and LV areas, top Blast identities with several uncultured bacteria, which were observed in a variety of sediments and also in coastal sediments vegetated by seagrasses (Jensen et al., 2007), apparently far from fecal pollution sources. These preliminary findings suggest that some of members within this family may be part of the natural benthic assemblages, and are thus not reliable indicators of fecal pollution. It is evident that, given also the much higher complexity of benthic microbial assemblages when compared with the planktonic ones, there is still much to be deciphered when using this type of community approaches to track fecal pollution in aquatic sediments. Overall, our results demonstrate that the coupled analyses of the diversity and magnitude of the three fecal signatures (traditional, fecal- and sewage-associated bacteria) are useful to discern among different pollution sources in the sediments of transitional, estuarine and coastal areas.

\section{CONCLUSIONS}

We have shown that a wide range of aquatic sediments in areas exposed to anthropogenic stressors host important proportions of traditional indicator bacteria, but also of alternative bacterial taxa that more specifically track the presence of fecal (human and animal) and sewage pollution. The magnitude and pattern of the complex fecal signature followed the expected gradients of microbial pollution, and provided information useful to identify the main sources of pollution in the two study sites. Our results also emphasize the opportunities that NGS techniques now offer to disentangle complex fecal pollution signals, and to source track and identify alternative fecal indicators in lagoon and marine sediments. 


\section{ACKNOWLEDGMENTS}

This work was possible thanks to funds granted to GML by the Programme RITMARE (SP3-WP2-A2 Strumenti innovativi per la valutazione degli effetti di contaminanti emergenti sulle comunità biologiche), the IPA Project BALMAS - Ballast Water Management System for Adriatic Sea Protection (project code $1^{\circ}$ STR/0005) funded by EU, the Short Term Mobility (STM) Program funded by the CNR, and partially to funds granted to GMQ by the Malware - Metagenomic study of microbial invasive species introduced by ballast waters project (funded by Lifewatch Italia). We sincerely thank Dr. Francesca Garaventa (ISMAR-CNR) for her help in sampling the PRP site, and similarly the crew of the research boat 'Litus' and Dr. Mauro Bastianini (ISMAR-CNR) for making sample collection possible in the LV site.

\section{REFERENCES}

An YJ, Kampbell DH, Breidenbach GP, 2002. Escherichia coli and total coliforms in water and sediments at lake marinas. Environ. Pollut. 120:771-778.

Bae S, Wuertz S, 2015. Decay of host-associated Bacteroidales cells and DNA in continuous-flow freshwater and seawater microcosms of identical experimental design and temperature as measured by PMA-qPCR and qPCR. Wat. Res. 70: 205-213.

Byappanahalli MN, Nevers MB, Korajkic A, Staley ZR, Harwood VJ, 2012. Enterococci in the environment. Microbiol. Mol. Biol. Rev. 76:685-706.

Boldrin A, Langone L, Miserocchi S, Turchetto M, Acri F, 2005. Po River plume on the Adriatic continental shelf: dispersion and sedimentation of dissolved and suspended matter during different river discharge rates. Mar. Geol. 222:135-158.

Caporaso JG, Kuczynski J, Stombaugh J, Bittinger K, Bushman FD, Costello EK, Fierer N, Pena AG, Goodrich JK, Gordon JI, Huttley GA, Kelley ST, Knights D, Koenig JE, Ley RE, Lozupone CA, McDonald D, Muegge BD, Pirrung M, Reeder J, Sevinsky JR, Turnbaugh PJ, Walters WA, Widmann J, Yatsunenko T, Zaneveld J, Knight R, 2010. QIIME allows analysis of high-throughput community sequencing data. Nat. Methods 7:335-336.

Casatta N, Stefani F, Pozzoni F, Guzzella L, Marziali L, Mascolo G, Viganò L, 2015. Endocrine-disrupting chemicals in coastal lagoons of the Po River delta: sediment contamination, bioaccumulation and effects on Manila clams. Environ. Sci. Pollut. Res. Int. 23:10477-10493.

Correggiari A, Cattaneo A, Trincardi F, 2005. The modern Po Delta system: lobe switching and asymmetric prodelta growth. Mar. Geol. 222:49-74.

Cucco A, Umgiesser G, 2006. Modeling the Venice Lagoon residence time. Ecol. Model. 193:34-51.

DeSantis TZ, Hugenholtz P, Larsen N, Rojas M, Brodie EL, Keller K, et al., 2006. Greengenes, a chimera-checked 16S rRNA gene database and workbench compatible with ARB. Appl. Environ. Microbiol. 72:5069-5072.
Edgar RC, 2010. Search and clustering orders of magnitude faster than BLAST. Bioinformatics 26:2460-2461.

Eiler A, Heinrich F, Bertilsson S, 2012. Coherent dynamics and association networks among lake bacterioplankton taxa. ISME J. 6:330-342.

Elliott JE, Elliott KH, 2013. Tracking marine pollution. Science 340: 556-558.

Field KG, Samadpour M, 2007. Fecal source tracking, the indicator paradigm, and managing water quality. Water Res. 41:3517-3538.

Fisher JC, Eren AM, Green HC, Shanks OC, Morrison HG, Vineis JH, Sogin ML, McLellan SL, 2015. Comparison of sewage and animal fecal microbiomes by using oligotyping reveals potential human fecal indicators in multiple taxonomic groups. Appl. Environ. Microbiol. 81:7023-7033.

Halpern BS, Walbridge S, Selkoe KA, Kappel CV, Micheli F, D'Agrosa C, et al., 2008. A global map of human impact on marine ecosystems. Science 319:948-952.

Jensen SI, Kühl M, Priemé A, 2007. Different bacterial communities associated with the roots and bulk sediment of the seagrass Zostera marina. FEMS Microbiol. Ecol. 62:108-117.

Kim M, Wuertz S, 2015. Survival and persistence of host-associated Bacteroidales cells and DNA in comparison with Escherichia coli and Enterococcus in freshwater sediments as quantified by PMA-qPCR and qPCR. Water Res. 87:182-192.

Kreader CA, 1995. Design and evaluation of Bacteroides DNA probes for the specific detection of human fecal pollution. Appl. Environ. Microbiol. 61: 1171-1179.

Liang L, Goh SG, Vergara GGRV, Fang HM, Rezaeinejad S, Chang SY, Bayen S, Lee WA, Sobsey MD, Rose JB, Gin $\mathrm{KYH}, 2015$. Alternative fecal indicators and their empirical relationships with enteric viruses, Salmonella enterica, and Pseudomonas aeruginosa in surface waters of a tropical urban catchment. Appl. Environ. Microbiol. 81:850-860.

Luna GM, Vignaroli C, Rinaldi C, Pusceddu A, Nicoletti L, Gabellini M, Danovaro R, Biavasco F, 2010. Extraintestinal Escherichia coli carrying virulence genes in coastal marine sediments. Appl. Environ. Microbiol. 76:5659-5668.

Luo C, Walk ST, Gordon DM, Feldgarden M, Tiedje JM, Konstantinidis KT, 2011. Genome sequencing of environmental Escherichia coli expands understanding of the ecology and speciation of the model bacterial species. P. Natl. Acad. Sci. USA 108:7200-7205.

Manini E, Luna GM, Danovaro R, 2004. Benthic bacterial response to variable estuarine water inputs. FEMS Microbiol. Ecol. 50:185-194.

McLellan SL, Eren AM, 2014. Discovering new indicators of fecal pollution. Trends Microbiol. 22:697-706.

Micheletti S, Gottardo A, Critto A, Chiarato A, Marcomini A, 2011. Environmental quality of transitional waters: the lagoon of Venice case study. Environ. Int. 37:31-41.

Newton RJ, Bootsma MJ, Morrison HG, Sogin ML, McLellan SL, 2013. A microbial signature approach to identify fecal pollution in the waters off an urbanized coast of Lake Michigan. Microb. Ecol. 65:1011-1023.

Newton RJ, VandeWalle JL, Borchardt MA, Gorelick MH, McLellan SL, 2011. Lachnospiraceae and Bacteroidales alternative fecal indicators reveal chronic human sewage contamination in an urban harbor. Appl. Environ. Microbiol. 77: 6972-6981 
Pachepsky YA, Shelton DR, 2011. Escherichia coli and fecal coliforms in freshwater and estuarine sediments. Crit. Rev. Environ. Sci. Technol. 41: 067-1110.

Palinkas CM, Nittrouer CA, Wheatcroft RA, Langone L, 2005. The use of 7 Be to identify event and seasonal sedimentation near the Po River delta, Adriatic Sea. Mar. Geol. 222:95-112.

Perini L, Quero GM, García ES, Luna GM, 2015. Distribution of Escherichia coli in a coastal lagoon (Venice, Italy): temporal patterns, genetic diversity and the role of tidal forcing. Water Res. 87:155-165.

Quero GM, Cassin D, Botter M, Perini L, Luna GM, 2015. Patterns of benthic bacterial diversity in coastal areas contaminated by heavy metals, polycyclic aromatic hydrocarbons (PAHs) and polychlorinated biphenyls (PCBs). Front. Microbiol. 6:1053.

Ridgway J, Shimmield G, 2002. Estuaries as repositories of historical contamination and their impact on shelf seas. Est. Coast. Shelf Sci. 55: 903-928.

Rock P, 2012. Urban gulls. Why current control methods always fail. Riv. Ital. Ornitol. 82: 58-65.

Romano S, Langone L, Frignani M, Albertazzi S, Focaccia P, Bellucci LG, Ravaioli M, 2013. Historical pattern and mass balance of trace metals in sediments of the northwestern Adriatic Sea Shelf. Mar. Poll. Bull. 76: 32-41.

Savichtcheva O, Okabe S, 2006. Alternative indicators of fecal pollution: relations with pathogens and conventional indicators, current methodologies for direct pathogen monitoring and future application perspectives. Water Res. 40: 2463-2476.

Scroccaro I, Ostoich M, Umgiesser G, De Pascalis F, Colugnati L, Mattassi G, Vazzoler M, Cuomo M, 2010. Submarine wastewater discharges: dispersion modelling in the Northern Adriatic Sea. Environ. Sci. Pollut. Res. 17: 844-855.

Sfriso A, Facca C, 2013. Annual growth and environmental relationships of the invasive species Sargassum muticum and Undaria pinnatifida in the lagoon of Venice. Est. Coast. Shelf Sci. 129:162-172.

Stewart JR, Gast RJ, Fujioka RS, Solo-Gabriele HM, Meschke JS, Amaral-Zettler LA, del Castillo E, Polz MF, Collier TK, Strom MS, Sinigalliano CD, Moeller PDR, 2008. The coastal environment and human health: microbial indicators, pathogens, sentinels and reservoirs. Environ. Health 7:S3.

Tan B, Ng C, Nshimyimana JP, Loh LL, Gin KY-H, Thompson JR, 2015. Next-generation sequencing (NGS) for assessment of microbial water quality: current progress, challenges, and future opportunities. Front. Microbiol. 6:1027.

Vandewalle JL, Goetz GW, Huse SM, Morrison HG, Sogin ML, Hoffmann RG, Yan K, McLellan SL, 2012. Acinetobacter, Aeromonas and Trichococcus populations dominate the microbial community within urban sewer infrastructure. Environ. Microbiol. 14: 2538-2552.

Vierheilig J, Savio D, Ley RE, Mach RL, Farnleitner AH, Reischer GH, 2015. Potential applications of next generation DNA sequencing of 16S rRNA gene amplicons in microbial water quality monitoring. Wat Sci Technol 72:1962-1972.

Vörösmarty CJ, McIntyre PB, Gessner MO, Dudgeon D, Prusevich A, Green P, Glidden S, Bunn SE, Sullivan CA, Liermann CR, Davies PM, 2010. Global threats to human water security and river biodiversity. Nature 67:555-561.

Zuliani A, Zaggia L, Collavini F, Zonta R, 2005. Freshwater discharge from the drainage basin to the Venice Lagoon (Italy). Environ. Internat. 31:929-938. 